\title{
COVID-19 International Evidence: Some Notable Puzzles
}

\section{CENTER FOR QUANTITATIVE ECONOMIC RESEARCH}

\author{
CENTER FOR HUMAN \\ CAPITAL STUDIES
}

\section{CENTER FOR FINANCIAL INNOVATION AND STABILITY}

CENTER FOR HOUSING AND POLICY

\section{Summary:}

This article uses international evidence to argue that we still have limited knowledge about the efficacy of widely used preventive actions, such as social distancing and face masks, in containing the spread of the novel COVID-19 virus. I document three puzzles. One, Peru enacted unprecedented lockdowns early in the pandemic, which led to a record contraction in economic activity. The country's residents also adopted near-universal face mask usage. None of these actions, however, prevented Peru from experiencing the world's highest per capita mortality rate from the virus. Second, southeast Asian countries practically did not register cases despite being closely interconnected to the source of the virus and adopting rather lax viruscontainment policies. Third, sub-Saharan African countries were largely spared from the virus, despite being considered very high-risk countries at the onset of the pandemic. I also discuss some emerging hypotheses that could explain these puzzles. Rather than rebuffing proven preventive actions like social distancing and face mask usage, this article highlights the limited knowledge we still have on this novel disease.

\section{Key findings:}

1. Considerable evidence shows that masks and social distancing reduce the spread of COVID-19, but my review of international evidence indicates other factors may be important as well. In this article, I highlight some puzzles observed in the international data.

2. Peru enacted very strict lockdowns and near-universal face mask usage early in the pandemic, but it could not avoid record deaths.

3. Many countries in southeast Asia recorded practically no COVID-19 cases, despite their proximity to the virus source and limited social distancing. Sub-Saharan Africa did remarkably well in containing the disease despite grim projections at the onset of the pandemic.

Center affiliation: Center for Quantitative Economic Research and the Americas Center JEL classification: E19, 119

Key words: COVID-19

https://doi.org/10.29338/ph2020-14

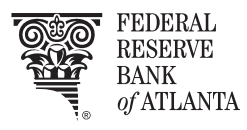

The Federal Reserve Bank of Atlanta's Policy Hub

leverages the expertise of Atlanta Fed economists and researchers to address issues of broad policy interest. Our research centers coordinate this work and seek to influence policy discussions. Areas of interest include: forecasting, fiscal policy, and macroeconomics (Center for Quantitative Economic Research); financial stability, innovation, and regulation (Center for Financial Innovation and Stability); human capital, labor markets, health, and education (Center for Human Capital Studies); and government-sponsored entity reform, mortgage markets, and affordable housing (Center for Housing and Policy). Sign up for email updates at frbatlanta. org/research/publications/policy-hub. 


\section{COVID-19 International Evidence: Some Notable Puzzles}

Summary: This article uses international evidence to argue that we still have limited knowledge about the efficacy of widely used preventive actions, such as social distancing and face masks, in containing the spread of the novel COVID-19 virus. I document three puzzles. One, Peru enacted unprecedented lockdowns early in the pandemic, which led to a record contraction in economic activity. The country's residents also adopted near-universal face mask usage. None of these actions, however, prevented Peru from experiencing the world's highest per capita mortality rate from the virus. Second, southeast Asian countries practically did not register cases despite being closely interconnected to the source of the virus and adopting rather lax virus-containment policies. Third, sub-Saharan African countries were largely spared from the virus, despite being considered very high-risk countries at the onset of the pandemic. I also discuss some emerging hypotheses that could explain these puzzles. Rather than rebuffing proven preventive actions like social distancing and face mask usage, this article highlights the limited knowledge we still have on this novel disease.

\section{About the Author:}

Federico S. Mandelman is a research economist and policy adviser at the Federal Reserve Bank of Atlanta and adjunct professor at Emory University.

Acknowledgments: The author thanks R. Anton Braun, Nikolay Gospodinov, John Robertson, Yongs Shin, and Tom Heintjes for very helpful comments. The views expressed here are the author's and not necessarily those of the Federal Reserve Bank of Atlanta or the Federal Reserve System. Any remaining errors are the author's responsibility.

Comments to the author are welcome at federico.mandelman@atl.frb.org. 


\section{Introduction}

The most visible worldwide impact of the COVID-19 pandemic on daily life is the widespread use of social distancing and face masks. Although evidence is mounting that both measures save lives, just how effective are they in preventing the spread of the disease? In this article, I review some confounding international evidence-namely, some countries with early adoption of strict social distancing and nearuniversal face mask usage suffered record virus deaths, while other nations that implemented only limited measures came out remarkably unscathed. In what follows, I discuss some of these puzzles and provide some emerging hypotheses aimed at explaining them.

\section{Peru: Record Low Mobility, Nearly Universal Face Mask Use, and the World's Highest Mortality Rate}

On March 15, 2020-just one week after the first COVID-19 case was recorded in Peru-President Martín Vizcarra announced one of the strictest nationwide lockdowns at the time. International borders were completely sealed, domestic travel was curtailed to a bare minimum, and nonessential business operations were completely shut down (healthcare facilities, food vendors, and pharmacies were the exceptions). Citizens were ordered to remain at home and allowed to leave only to get food or medical care. This curfew was eventually extended for months and was patrolled by both the police and the military. Repeat offenders were arrested.

The effective implementation of these restrictions resulted in a decline in public transportation ridership of 88 percent in the capital city of Lima-by far the biggest decline in Latin America. These numbers are consistent with those shown in Google's community mobility database (see figure 1). These reports are particularly useful in this context. Cellphone use is widespread in Latin America and practically universal in large urban areas. ${ }^{1}$ The data show that in the first eight weeks of the lockdown, mobility on a national level remained 80 percent below pre-pandemic levels. This decline in mobility was notably persistent: in mid-August, mobility was still 60 percent below normal. In contrast, U.S. data show that the lockdown was much milder, with mobility never declining more than 50 percent at the national level. It was also short lived, with mobility hovering just 20 percent below normal by summer.

\footnotetext{
${ }^{1}$ Around 98 percent of the region's population have coverage by a mobile cell signal, and 84 percent of Latin American households have mobile service, with Google's Android being the dominant operating system. Across the developing world, these numbers are similar in most urban areas .
} 


\section{Figure 1: Google's COVID-19 Community Mobility Data}

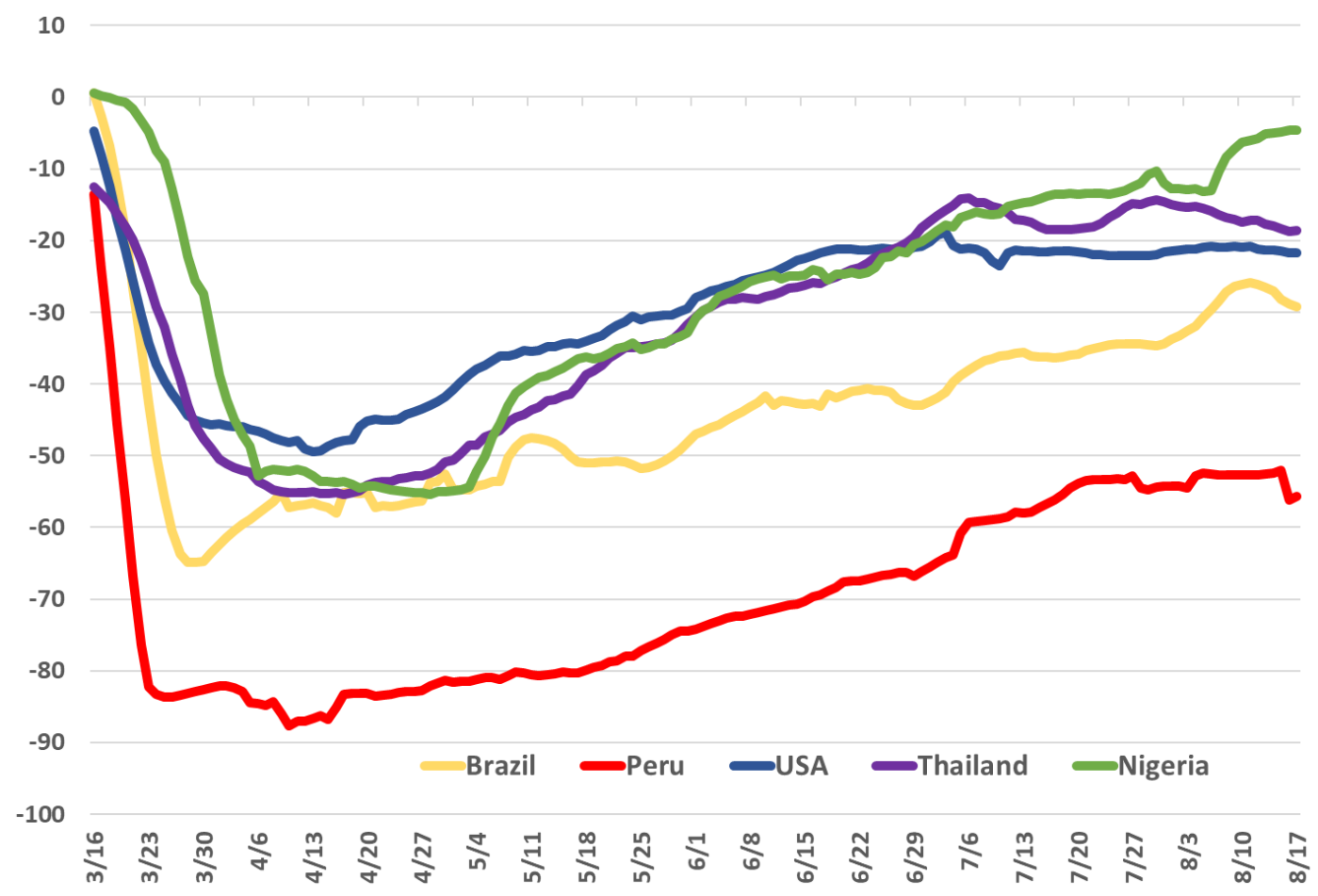

Note: The index indicates average retail and transit travel and depicts seven-day moving averages. Data are expressed as percentage declines from the starting period.

Source: Google's Community Mobility Reports

Peru's strict lockdown policy walloped the economy. Gross domestic product (GDP) contracted by 72 percent in the second quarter of 2020 and is expected to be the worst global performer, falling by a total of 13 percent in 2020, according to the Economist Intelligence Unit (see figure 2). ${ }^{2}$ Although still deep, the U.S. COVID-19 recession pales in comparison. GDP fell 31 percent in the second quarter and is expected to shrink by only about 4 percent in 2020 .

\footnotetext{
${ }^{2}$ Data are for the group of countries for which forecasting estimates are currently available.
} 


\section{Figure 2: Real GDP Growth for Selected Countries}

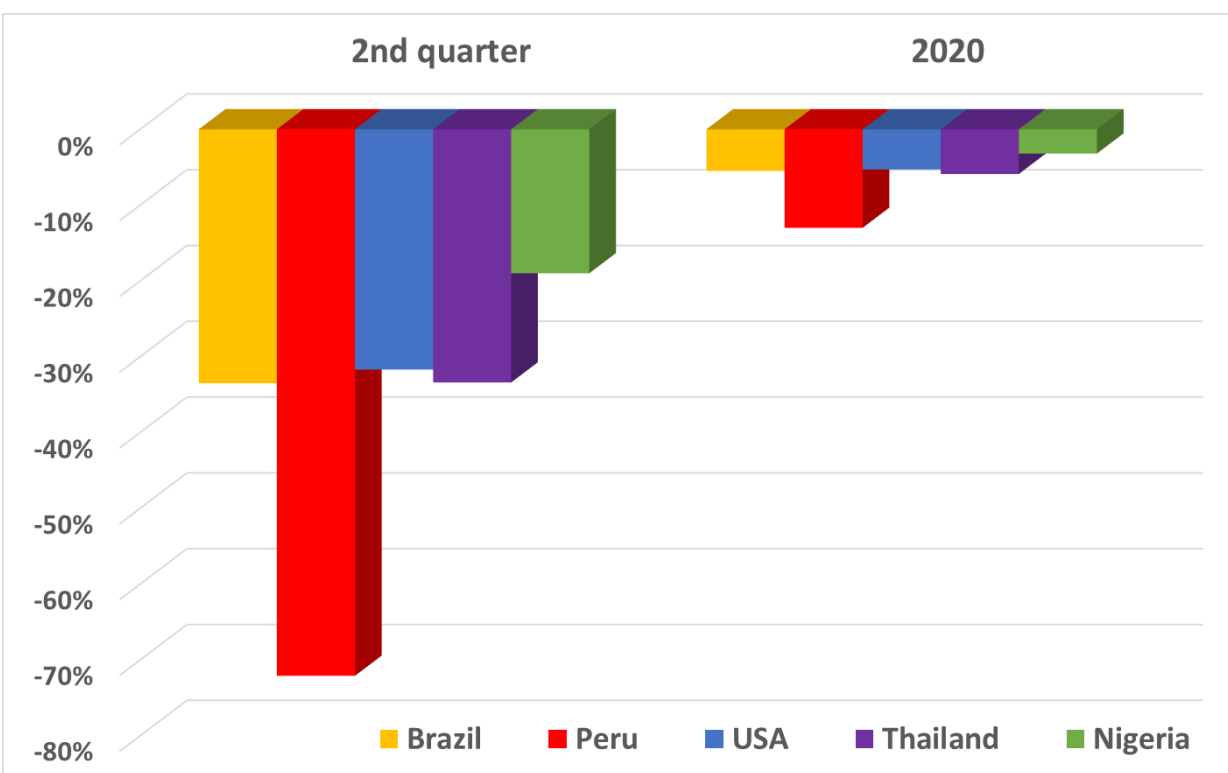

Source: Economist Intelligence Unit and the Central Bank of Nigeria

Another fundamental factor to consider when assessing the extent of social distancing is face covering. A clear consensus has emerged in the scientific community on this front: face masks are useful not only in containing the spread of the disease but also in reducing the severity of it. Nature, a globally respected, peer-reviewed scientific journal, recently presented a summary of the growing empirical evidence supporting this claim. For instance, this journal reports that weekly increases in per capita mortality rates were four times lower in places where face masks were the norm (relative to where they were mostly absent).

Peru was an early and widespread adopter of face masks. On April 3, the Peruvian government mandated the wearing of face masks in all public premises. This policy mandate was effectively implemented, and face masks became practically universal by then end of April, with 90 percent nationwide use. ${ }^{3}$ Figure 3 illustrates this evidence, which was collected by the Institute for Health Metrics and Evaluation (IHME) at the University of Washington. This early and nearly universal adoption in Peru is particularly notable when considering that both the World Health Organization (WHO) and the U.S. Centers for Disease Control and Prevention (CDC) initially refrained from recommending widespread masking.

\footnotetext{
${ }^{3}$ The Institute for Health Metrics and Evaluation at the University of Washington, which collected these data, considers countries to have reached universal mask usage when usage crosses the 95 percent threshold.
} 


\section{Figure 3: Face Mask Use in Public}

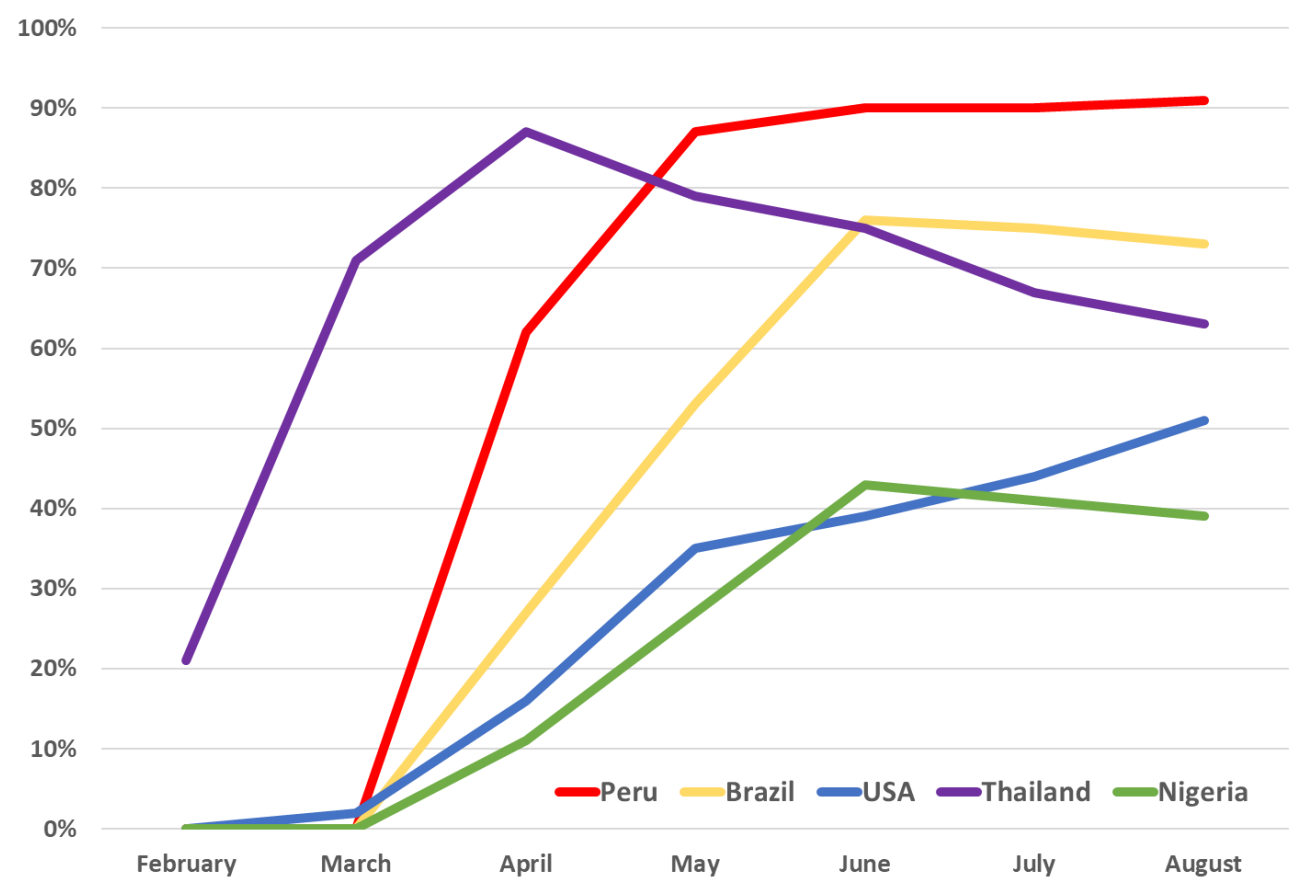

Source: Institute for Health Metrics and Evaluation at the University of Washington

Not until April did the $\mathrm{CDC}$ recommend mask wearing when physical distancing was not feasible. The WHO followed suit only in June. As a result, mask usage was much more limited in the United States. Only 10 percent of Americans wore face masks in public in April, and usage has increased very slowly since then (stabilizing at 50 percent since August). Low face mask use in the United States reflects not only the inconsistent policy guidelines among these leading health policy institutes, but also the politicization of face mask use.

This all raises a question: if Peru implemented early and very strict lockdowns (at the cost of a record economic contraction) and quickly adopted near-universal face mask usage, how well did Peru do in limiting the spread of COVID-19 and the number of COVID-19 deaths?

The results are beyond dismal: to date, Peru suffered the world's highest per capita COVID-19 mortality level. At the time of writing this the article, ${ }^{4}$ Peru has recorded 33,875 deaths. With a total population of 32 million, this represents 106 deaths per 100,000 individuals and places Peru atop the world rankings. As a reference, the U.S. mortality rate is 68 per 100,000 , about 36 percent lower. Why did Peru do so badly? This is perhaps the most intriguing puzzle when assessing the international evidence. More telling is the comparison with neighboring Brazil. In contrast with the Peruvian head of state, President Jair Bolsonaro repeatedly downplayed the threat of the virus and spoke out against social distance policy measures. Most state governors in Brazil, however, repeatedly challenged

\footnotetext{
${ }^{4}$ All numbers were updated on October 27, 2020.
} 
Bolsonaro's stance and enacted their own social-distancing measures. These disagreements were amplified by a deeply politically polarized society, which led to a patchy implementation of socialdistancing measures. In contrast to Peru, Brazil experienced a milder decrease in mobility (as figure 1 shows), sparser mask usage (as figure 2 shows), but also a much milder economic contraction (seen in figure 3). While Brazil was hit hard by COVID-19, its mortality rate of 74 per 100,000 is still 30 percent lower than Peru's despite much less enforcement of social distancing. These differences are even more striking because the neighboring countries have a similar age structure and degree of economic development.

It is not difficult to encounter other puzzling experiences in Latin America, the region so far most affected by the virus. Argentina's response was like Peru's. Argentina enacted very strict social distancing measures, and its economy is expected to contract 11 percent this year. Taking this step has not prevented Argentina from reaching the fifth position in the COVID-19 world ranking for total COVID19 cases in October. Uruguay, Argentina's neighbor, refrained from implementing mandated lockdowns or curfews and merely encouraged civil responsibility. Yet Uruguay thus far reports only 53 deaths related to COVID-19.

Figure 4 shows daily COVID-19 deaths per 100,000 people, and it depicts some informative dynamics. ${ }^{5}$ For Peru, the mortality rate increased very slowly but then reached a high plateau with a steady death count afterward. The U.S. dynamics were notably different. Casualties peaked in early April and quickly decreased thereafter. A second wave appeared in Sun Belt states in the summer, while a third wave is currently engulfing the Midwest. Peru's experience with a slow but persistent increase in mortality is common in Latin America. Brazil is roughly the same geographic size as the United States but did not register the wave pattern we have seen in the United States and Western Europe. One potential factor that might explain this pattern is that the pandemic arrived in Latin America right at the end of the summer. Some studies show that the decrease in UV radiation, which begins with the start of the fall equinox, may increase the severity of the disease. ${ }^{6}$

\footnotetext{
${ }^{5}$ Due to lack of extensive testing capabilities in developing countries, total mortality is a more accurate indicator of the spread of the disease than simply counting infected individuals.

${ }^{6}$ See preliminary evidence for seasonality of COVID-19 due to ultraviolet radiation by Karapiperis et al.
} 


\section{Figure 4: Daily COVID-19 Deaths per 100,000 People}

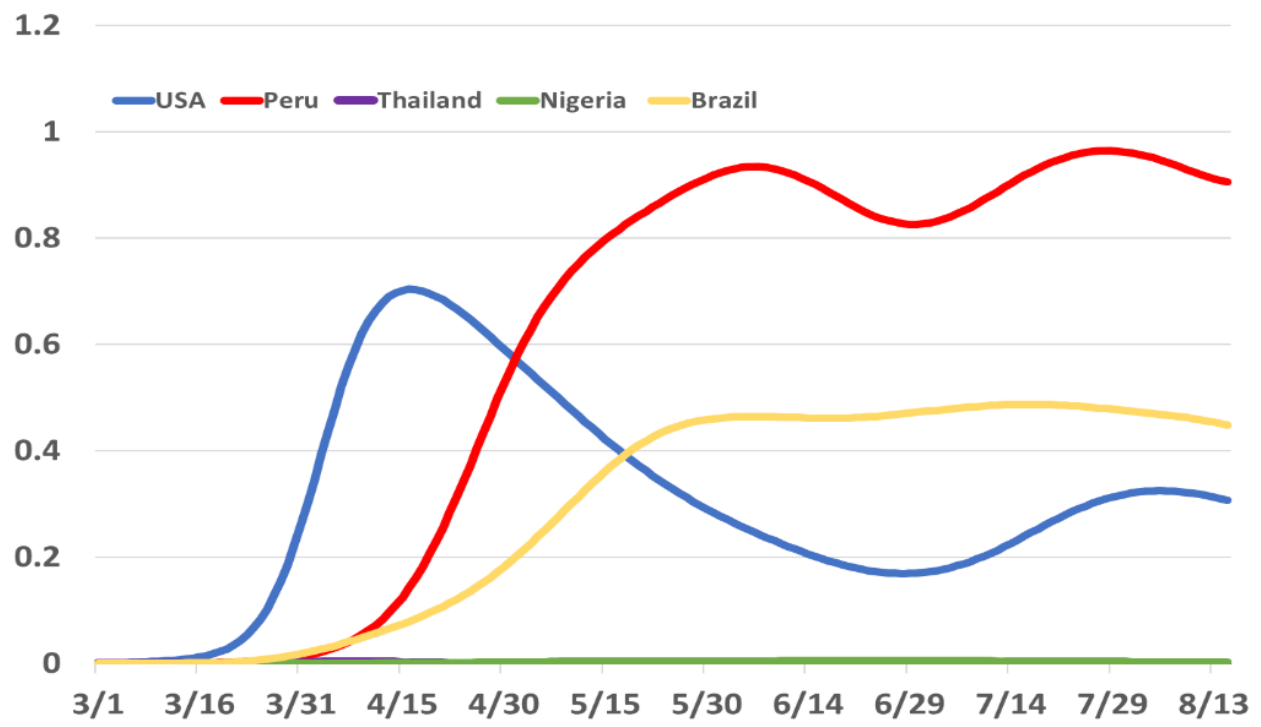

Note: Data indicate daily deaths per 100,000 people.

Source: Institute for Health Metrics and Evaluation (IHME) and the University of Washington

The evidence presented in this section should not be interpreted as refuting the importance of social distancing in containing the extent and severity of the pandemic because, simply put, we do not have a counterfactual. It is possible that the health situation in Peru would have been much worse without strict social distancing mandates. It is also possible that the other countries mentioned would have done much better with stricter social distancing policies.

\section{Thalland: Largely Spared from COVID-19 Despite Being Close to Its Birthplace}

While Latin America was the region most battered by the pandemic, East Asia has, to date, remained relatively unscathed despite being the birthplace of the pandemic. To explain this success, epidemiologists focused their attention on the unprecedented containment efforts enacted by some countries in the area.

China originally neglected, and arguably underreported, the spread of the disease. Still, China eventually took unprecedented measures to contain the pandemic. Early in March, about 800 million people were essentially prohibited from leaving their homes, and widely seen images of ghost towns emerged from all over the country. Widespread testing was also quickly implemented. A longstanding infrastructure of state surveillance facilitated contact tracing, and China rapidly controlled its virus outbreak.

With fewer than one death per 100,000 people, South Korea's elaborate contact tracing network has received wide praise. Cellphone tracking, credit card transactions, and even closed-circuit television footage was used to reconstruct and contain infection pathways. Taiwan, which as of this writing has registered only seven deaths, implemented somewhat similar policies and obtained similar praise. 
Other countries in Asia have received less attention but have also experienced low death rates. Thailand, with a population of 69 million, has registered only 59 deaths. Moreover, Thailand has some peculiarities that made its extremely low infection rate particularly notable. The country is a leading tourist destination among Chinese travelers eager to escape the China's cold winters. The New York Times reports that, on average, 900 people fly from Wuhan, China, to New York every month, while 15,000 Chinese people travel monthly to Bangkok, Thailand. Thailand is very attractive during the Lunar New Year in January, which this year coincided with the virus outbreak. (Notably, international travel remained largely unregulated in January, since Chinese authorities acknowledged the risk of human-tohuman COVID-19 transmission only at the very end of the month.)

Consequently, it took no one by surprise when Thailand announced the first COVID-19 infection outside of China on January 13, 2020. Dire projections for the virus transmission in Thailand followed. Bangkok's metro area is large, with a population of 14 million, but also crowded into a small area along the Chao Phraya River. Sanitary conditions are far from ideal, as most houses lack proper plumbing and waste treatment. As in most developing countries, testing was also very limited. For instance, as of May 4, the number of COVID-19 tests per capita was just 21 percent of the level of South Korea. Taken together, these considerations made contact tracing in Thailand a hopelessly daunting task.

Against all odds, Thailand barely felt the virus. Despite limited testing, the positivity rate was just 1 percent and, as previously mentioned, only 53 people have died from the virus to date. Figure 4 depicts Thailand's fatality rate, although it is so close to zero that it is hard to see. The remaining figures show that Thailand's reduction in community mobility-as well as its decline in GDP-were in line with the U.S. experience. Perhaps the only notable difference between Thailand and the United States was the early and widespread adoption of face masks in Thailand (which were already commonly worn prior to the pandemic). Although this section of the article focuses on Thailand, I want to highlight the fact that the virus left other, even less developed, neighboring countries in the Indo-Chinese peninsula practically untouched, despite their proximity to its point of origin. Taken together, Laos, Cambodia, and Vietnam - with a collective population of more than 120 million-suffered only 35 deaths.

Proximity to China and frequent contact with Chinese nationals may be a factor behind the low death rates in this region. Researchers recently found that the southern Chinese province of Yunnan possesses a family of coronaviruses closely related to SARS-CoV-2, the virus responsible for the COVID19 pandemic. This province borders the Indo-Chinese peninsula, which leads to some hypotheses that the inhabitants of this area had already built up some immunity to these pathogens.

\section{Sub-Saharan Africa: The Anticipated Tragedy That Never Came to Pass}

With the Ebola pandemic (2013-16) still fresh in the minds of many, many epidemiologists in the early stage of the COVID-19 outbreak were particularly worried about how COVID-19 would affect subSaharan Africa. A variety of reasons justified this concern: namely, a severely deficient health care system typically lacking the most basic medical supplies, widespread testing facility shortfalls, and densely populated urban areas, with the poorest, often malnourished residents in squatter settlements. Fortunately, these fears were largely unrealized. Except for South Africa, all sub-Saharan African countries have mortality rates below seven per 100,000 people (easily putting most of them at the 
bottom of the world rankings on mortality rates). South Africa is the outlier, with 33 deaths per 100,000, but still well below most countries in the Americas and Western Europe.

Scientists struggle to explain why this region has been largely spared from the virus. Indeed, Recent antibody tests experiments appear to show that the virus spread swiftly in sub-Saharan Africa. In Mozambique and Malawi, for instance, the presence of antibodies in the asymptomatic population ranges between 3 percent to 12.6 percent. However, very few appeared to develop the disease. The figures in this Policy Hub article illustrate the case of Nigeria. With 206 million people, the country has the continent's largest population, and the WHO identified it early in the pandemic as at high risk for the spread of COVID-19. Nigeria is a major oil producer, and demand for oil collapsed as COVID-19 spread across the globe. Yet Nigeria experienced a small reduction in mobility, and its GDP contracted less compared to all the other countries I have discussed. Although the use of face masks was rare in Nigeria, the impact of COVID-19 has been small. The 1,135 deaths reported to date from the virus are almost negligible given Nigeria's large population.

The age distribution of the population is one evident factor that can explain these encouraging results. It is well known that in the developed world, those who are 65 years and older account for approximately 75 percent of the total deaths. Only 3 percent of the population in sub-Saharan Africa is older than 65. In Europe, that share is 18.5 percent. Another hypothesis is that extreme poverty results in regular exposure to pathogens such as malaria and other infectious diseases, which may ultimately boost immunity to coronaviruses. Still this hypothesis faces some challenges, particularly when comparing the positive figures in Africa and Asia with the poor outcomes in Latin America. The Latin American population is also relatively young, with less than 8.5 percent of the population older than 65 . Moreover, the poorest Latin Americans were about three times more likely than the rich to die from the disease. This group-which also has the lowest income-also tends be relatively young and is routinely exposed to mosquito-borne pathogens (such as Dengue, Zika, and Chikungunya viruses) in large, crowded settlements with poor sanitary conditions.

\section{Final Remarks}

It would be a mistake to conclude from the evidence I have presented here that proven preventive actions like social distancing and face mask usage play no role in combating a disease destined to be a strange twist of fate with a huge variation in global outcomes. If anything, these experiences highlight the limited knowledge we still have in making a medical prognosis and understanding the community diffusion of this novel disease. The extraordinary, multidisciplinary scientific research effort currently under way will hopefully ultimately shed more light on the issues I have raised here. 